\title{
CONTRIBUTION OF NEUTRON TOMOGRAPHY TO 3D HETEROGENEITY ANALYSIS OF GRANITIC ROCKS
}

\author{
Ivan Yu. ZEL 1), Matěj PETRUŽÁLEK ${ }^{2)}$ *, Sergey E. KICHANOV ${ }^{1)}$, Kuanysh M. NAZAROV 1, 3), \\ Tomáš LOKAJÍČEK ${ }^{2)}$, Denis P. KOZLENKO ${ }^{1)}$, Ivana TURKOVÁ ${ }^{4)}$, \\ Marek KOTRLÝ ${ }^{4)}$ and Radek ONYSKO ${ }^{4,5)}$
}

\author{
1) Joint Institute for Nuclear Research, Frank Laboratory of Neutron Physics, 141980 Dubna, Moscow Region, Russia \\ 2) Institute of Geology AS CR v.v.i., 16500 Prague, Czech Republi \\ 3) Faculty of Physics and Technical Sciences, L.N. Gumilyov Eurasian National University, 010008, Nur-Sultan, Kazakhstan \\ 4) Institute of Criminalistics, 17089 Prague, Czech Republic \\ ${ }^{5}$ SG Geotechnika, a.s., 15200 Prague, Czech Republic \\ *Corresponding author's e-mail: petruzalek@gli.cas.cz
}

\begin{tabular}{l} 
ARTICLE INFO \\
\hline Article history: \\
Received 25 March 2020 \\
Accepted 16 June 2020 \\
Available online 5 August 2020
\end{tabular}

Keywords:
Neutron tomography
Mica spatial distribution
Granite
Heterogeneity
Anisotropy
Bohemian Massif

Bohemian Massif

\begin{abstract}
Volumetric studies of mica spatial distribution inside samples of Westerly and Czech granites (Mrakotin, Liberec, and Brno syenite) were performed using a neutron tomography method. A significant difference in the neutron attenuation coefficients of mica and other rock-forming minerals of the granites studied yielded a large neutron radiography contrast and, as a result, allowed us to perform a detailed analysis of three-dimension structural data based on the neutron tomography reconstruction procedure. The morphology and spatial distribution of the mica phase within studied granites were obtained. Tomography data were compared to results provided by other experimental methods commonly used in rock mechanics research such as optical and electron microscopy, as well as ultrasonic shear-wave measurements. The benefits and limitations for application of the neutron tomography method for studies of granite like rocks are discussed.
\end{abstract}

\section{INTRODUCTION}

Largely due to microscale heterogeneity, rock materials exhibit wide range in their physical properties. In low porous intact rocks, such scatter depends on the compositional distribution within rock volume, namely: grain size, grain shape, grain preferred orientation, crystallographic orientation, and microcrack alignment. The intrinsic anisotropy of individual grains, together with contributions of microstructural heterogeneity, causes deviations of rock properties from isotropy. Aside from crystallographic texture (the preferred crystallographic orientation of grains) that is the major source of anisotropy in textured rock, grain morphology is found to be important for the seismic (Vasin et al., 2014), magnetic (magnetite grains, Grégoire et al., 1998) anisotropy, electrical, and thermal (Jones and Friedman, 2000; Siegesmund and Dürrast, 2010) properties of rocks. Compositional variation expressed by the spatial localization of certain mineral phases may strongly contribute to variation in measured rock properties. The special case of horizontal layering has long been recognized as an indicator for the anisotropy of seismic, mechanical, and transport properties (Backus, 1962; Pribnow and Umsonst, 1993; Parkhomenko, 1967).
In most geological studies, an assumption of ergodicity (Shermergor, 1977), occurring when an average over phases equals an average over volume, is declared. However, in laboratory measurements of rock specimens, this condition may not always be fulfilled mostly due to the scale-dependency of measured properties. The behavior of rock under testing imposed by heterogeneity is directly seen in ultrasonic sounding (Murphy el al., 1984; Scales and Malcolm, 2003), thermal conductivity imaging (Jorand et al., 2013), and coda wave interferometer measurements (Grêt et al., 2006). Apparently, the most important dependency for rock heterogeneity is exhibited by mechanical properties. Numerous experimental and numerical studies (Cowie and Walton, 2018; Přikryl, 2006; Shushakova et al., 2010) have indicated a correlation between measured strength and/or deformative properties and the microstructural aspects of tested rocks (mineral composition, grain size, shapes, and 3D distribution). In the case of mechanical properties, micas present the highest heterogeneity contrast in rock forming minerals. As such, its volume distribution and its preferential orientation have a strong influence on mechanical properties of mica bearing rocks (Cowie and Walton, 2018) and predetermine the way of their failure (e.g. Petružálek et al., 2019). 

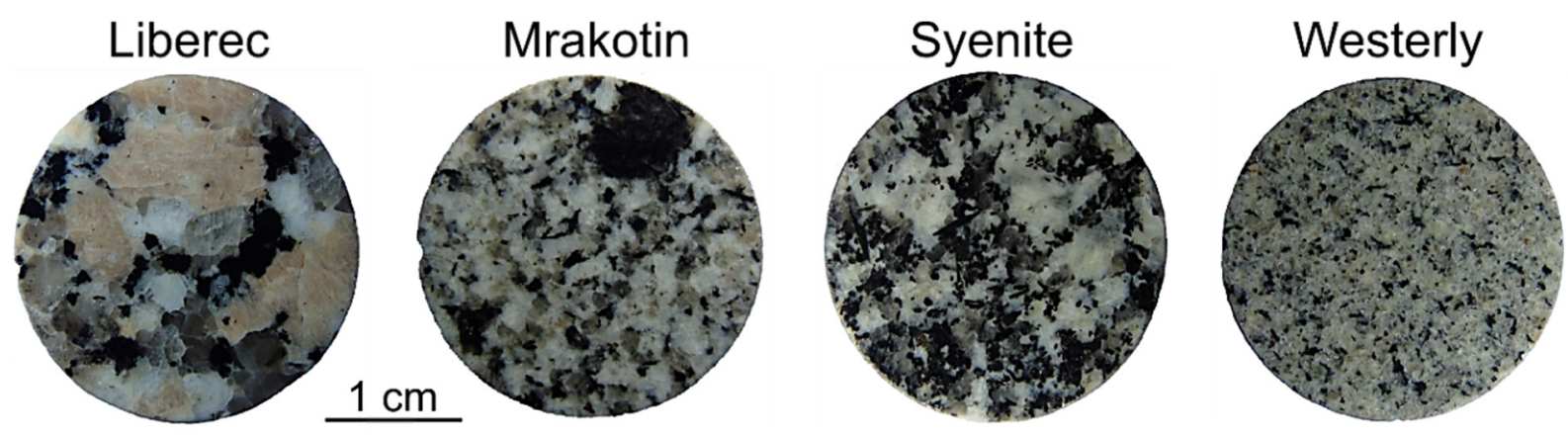

Fig. 1 A photo of the polished upper surfaces of the studied granite disks. Rock forming minerals differ by color: black - biotite, gray - quartz, pink - orthoclase, white - plagioclase and muscovite.

Recently, finding and correctly applying experimental methods for studying the internal volume of large rock mechanic specimens has been required. Neutron scattering methods are known to be characterized by exceptional penetration into massive matter. One of these corresponding neutron methods is that of neutron radiography and tomography (Strobl et al., 2009; Boone et al., 2014). The method belongs to the family of non-destructive testing methods and analysis, and plays an important role in industrial and scientific research. The fundamental difference in the nature of neutron interaction with matter as compared to X-rays provides additional benefits to neutron methods, including a sensitivity to light elements such as hydrogen-contained mica minerals and high penetration ability (Vontobel et al., 2005). All of these features make neutron tomography an attractive tool with a growing range of applications in industry (Strobl et al., 2009), archaeology (Kichanov, 2018), and geophysics (Vontobel et al., 2005), where providing structural information on the spatial distribution of internal components inside large volumes of rocks is desired.

For this work, we studied several typical micabearing granites that act as model rock samples with varying degrees of heterogeneity in mica grain morphology and distribution within the volume. Samples analyzed included Mrakotin, Liberec, Westerly granite, and Brno syenite. Here, threedimensional (3D) structural data, as well as the results of the corresponding analysis, are reported. The experimental possibilities of neutron tomography are compared to commonly used optical and electron scanning microscopy. The dependency of granite mechanical properties on mica volumetric distribution was demonstrated using shear wave ultrasonic sounding.

\section{EXPERIMENTAL}

\subsection{SAMPLE CHARACTERIZATION}

Four granitic rocks with different grain sizes and a similar mineral content were analyzed. Mrakotin granite, Brno syenite, and Liberec granite belong to the group known as variscan granites and in the Czech Republic they are widely used as building stone. Due to its rather homogeneous structure (Petružálek et al., 2020), Westerly granite (Rhode Island, USA) was chosen as a reference rock sample. The mechanical properties of all four tested granites are summarized in (Petružálek et al., 2017). Granite samples were given the shape of discs with a diameter of $25 \mathrm{~mm}$ and a thickness of $10 \mathrm{~mm}$ (Fig. 1).

The mineral composition of samples was obtained from an electron microscope MIRA 3 (TESCAN, Czech Republic) equipped with a TESCAN Integrated Mineral Analyzer (TIMA, TESCAN, Czech Republic) (Hrstka et al., 2018). The TIMA system operates on the principle of energy dispersive X-ray spectroscopy (EDS) combined with the detection of backscattering electrons (BSE). The electron beam continuously scans the total surface of the sample and the classical EDS analysis of X-ray radiation begins once the threshold energy of $\mathrm{BSE}$ brightness is exceeded. The polished sides of disks were scanned using a resolution of $4 \mu \mathrm{m}$. Quartz, plagioclase, orthoclase, and mica (muscovite + biotite) minerals are the main mineral phases of the studied granites. The estimated mineral composition of granites obtained from electron microscopy data is provided in Table 1. In the Brno syenite sample, an actinolite phase (approximately $10 \%$ ), existing as needle-like grains, was also determined.

Granite samples differ in the grain size of rockforming minerals. According to the TIMA TESCAN analysis, Liberec granite is a coarse-grained rock containing the largest grains of orthoclase $(\sim 12 \mathrm{~mm})$ and quartz $(\sim 8 \mathrm{~mm})$. Syenite also has large grains of orthoclase of approximately $7 \mathrm{~mm}$. In both Mrakotin and syenite samples, plagioclase and quartz grains are of the same maximum size $(\sim 2.5 \mathrm{~mm})$. Fine-grained Westerly granite has almost equisized grains $(\sim 0.7 \mathrm{~mm})$ of a quartz-plagioclase-orthoclase matrix. The size of mica grains in all samples was in the range of 0.4-3 mm, with the exception of one large grain $(\sim 6 \mathrm{~mm})$ found in Mrakotin and visible in Figure 1.

\subsection{NEUTRON TOMOGRAPHY}

Neutron tomography experiments were performed at the neutron radiography and tomography facility on beamline 14 of the IBR-2, high-flux pulsed 
Table 1 The estimated composition of major mineral phases of studied granites obtained by the TIMA TESCAN analysis.

\begin{tabular}{lcccc}
\hline Sample & Quartz (\%) & Plagioclase (\%) & Orthoclase (\%) & Micas (\%) \\
\hline Liberec & 29.62 & 26.12 & 33.94 & 8.09 \\
Mrakotin & 33.85 & 26.97 & 21.69 & 13.95 \\
Syenite & 24.52 & 20.01 & 28.29 & 15.73 \\
Westerly & 24.23 & 40.52 & 25.94 & 7.14 \\
\hline
\end{tabular}

a)

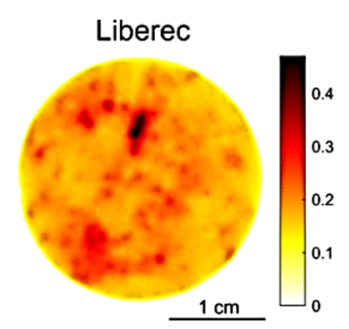

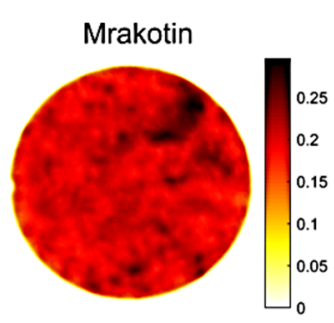
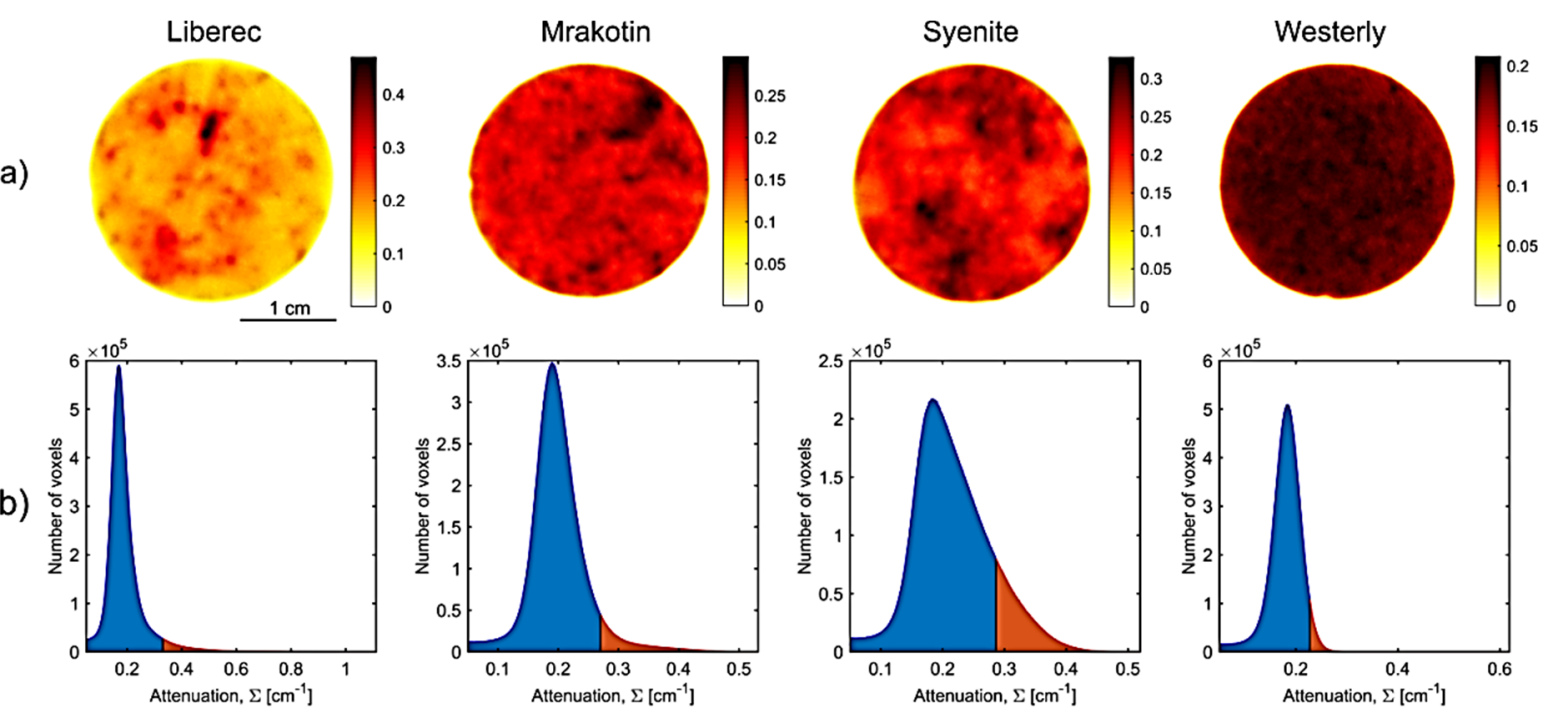

Fig. 2 a) Images corresponding to the transverse radiography of granite disks. The color schema «hot» indicates neutron absorption degree from low (white) to high (black). The color bar indicates attenuation coefficients in $\mathrm{cm}^{-1}$. Sample orientation is the same as in Figure 1b) The integral over the disk volume histograms of studied granite samples. The orange color on histograms marks the range of attenuation coefficients attributed to the mica phase.

reactor (Kozlenko et al., 2016). The IBR-2 reactor provides a thermal neutron beam with wavelengths ranging from $\sim 0.2$ to $8 \AA$ and a spectral distribution maximum of $\sim 1.8 \AA$. Neutron flux at the sample position was $\sim 5.5(2) \times 10^{6} \mathrm{n} / \mathrm{cm}^{2} / \mathrm{s}$ and the total neutron fluence was $\sim 2 \times 10^{10} \mathrm{n} / \mathrm{cm}^{2}$ during the time of the experiment. A set of neutron radiography images was collected using a CCD-based detector system with a maximum field of view of $20 \times 20 \mathrm{~cm}$ (Kozlenko et al., 2016). Tomography experiments were performed with a rotation step of $0.5^{\circ}$ and the total number of measured radiography projections was 360 . The exposure time for one projection was $20 \mathrm{~s}$ and measurements lasted for $4 \mathrm{~h}$.

Imaging data were corrected by subtracting the camera dark current image and normalizing it to an image of the incident neutron beam using ImageJ software (Schneider, 2012). Tomographic reconstruction was performed using H-PITRE software (Chen, 2012). Finally, a large dataset containing a volume distribution of 3D pixels (voxels) was collected. In our studies, the size of one voxel is $50 \times 50 \times 50 \mu \mathrm{m}$. Each of the voxels is characterized by spatial coordinates within the reconstructed $3 \mathrm{D}$ volume and a shade of gray color, corresponding to the value of the neutron attenuation coefficient within some points of the sample. The $3 \mathrm{D}$ volume data of voxels describes the spatial distribution of values for neutron absorption coefficients inside the total granite volume. Tomography reconstruction yielded a set of approximately 200 virtual slices for each studied granite disk, with a thickness of $50 \mu \mathrm{m}$. Due to spatial resolution, the neutron tomography facility has some restrictions on the minimum size of a resolved item up to 150 microns or $0.003 \mathrm{~mm}^{3}$ (Kozlenko et al., 2016).

The VGStudio MAX 2.2 software of Volume Graphics (Heidelberg, Germany) was used for the visualization and analysis of reconstructed $3 \mathrm{D}$ data.

\section{RESULTS AND DISCUSSION \\ 3.1. NEUTRON TOMOGRAPHY DATA AND ANALYSIS OF THE SPATIAL DISTRIBUTION OF MICA GRAINS INSIDE GRANITES}

Granite disks were correspondingly arranged in the neutron beam direction such that the rotation axis of disks coincided with the rotation axis within the tomographic experiment. As such, transversal virtual slices following the tomography reconstruction procedure corresponded to the polished surface slices of the studied granites (Fig. 1). Measured neutron radiographic images of the studied granite disks are provided in Figure 2a.

Each pixel within the tomography slices corresponds to the attenuation coefficient of the neutron beam at a local point on the granite disk. Attenuation of the neutron beam corresponds to 

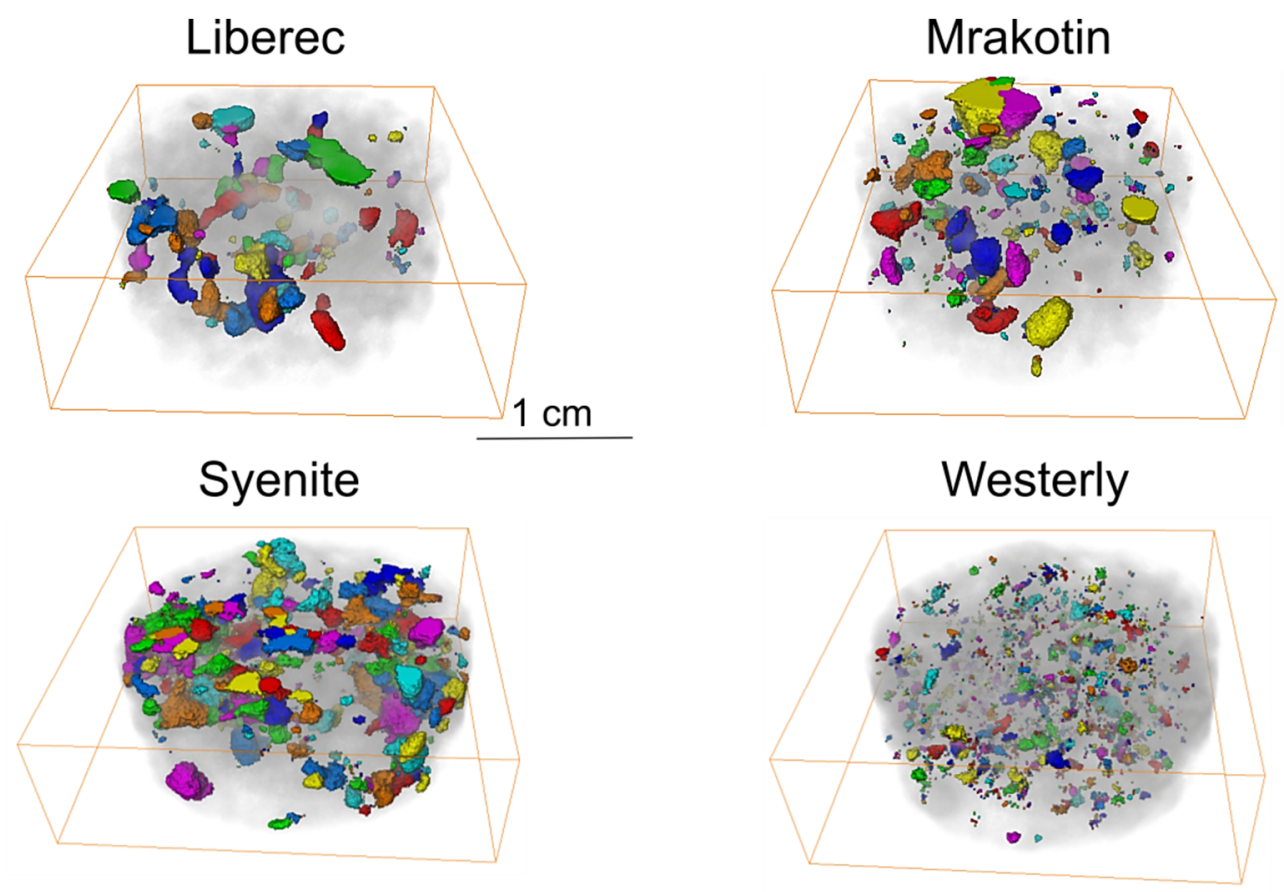

Fig. 3 The distribution of separated mica grains in granite samples obtained following the reconstruction of neutron tomography data. Colors correspond to different grain sizes. The gray shadow indicates the quartz/feldspar matrix of rock samples.

scattering and absorption losses inside the matter (Sears, 1992). Neutron attenuation coefficients for the neutron beam, with an average wavelength of $\sim 2 \AA$, is larger for mica minerals due to strong incoherent neutron scattering on hydrogen-containing components (Sears, 1992). Therefore, the mica grains contrast well with quartz and feldspar minerals within the neutron radiography experiments. Separation of 3D models of granites, by following mica and matrix phases assignments, were made by splitting the graylevel scale. Integral histograms or the $3 \mathrm{D}$ pixel (voxels) distribution on the attenuation coefficient scale for each investigated granite over total disk volume are provided in Figure $2 \mathrm{~b}$. All of the obtained diagrams are similar, having an asymmetric shape with long tails, corresponding to highly attenuative mica grains. As such, for Liberec granite, the maximum value of the attenuation coefficient of $\sim 1 \mathrm{~cm}^{-1}$ is close to those calculated for pure muscovite, annite, phlogopite, and chlorite (Boone et al., 2014; Christe et al., 2007). The attenuation coefficients for the mica of studied granites did not exceed $0.6 \mathrm{~cm}^{-1}$. Peak values on diagrams corresponded well to the expected attenuation coefficients for quartz and feldspars, $\Sigma \sim 0.26-0.29 \mathrm{~cm}^{-1}$ (Boone et al., 2014; Christe et al., 2007). The large skew of the probability distribution for syenite granite towards higher attenuation values (Fig. 2b) was caused by the actinolite phase. The attenuation coefficient, $\Sigma$, for the actinolite mineral was $0.71 \mathrm{~cm}^{-1}$ and fell within the range between mica and quartz/feldspar (Christe et al., 2007). 3D models of mica grain distribution inside granite samples following segmentation and separation procedures are provided in Figure 3.

The morphological and volumetric parameters of mica grains inside granite disks were analyzed using common procedures in terms of the maximum Feret diameter and particle breadth (Merkus, 2009). The shape of mica grains was analyzed using the aspect ratio $\left(\frac{\text { breadth }}{\text { length }}\right)$. Based on obtained $3 \mathrm{D}$ data, we calculated distributions of length and the aspect ratio of mica grains in granites (Figure 4).

Westerly granite, as the reference sample, is characterized by small grains of mica with sizes up to $2 \mathrm{~mm}$ and an average length of $0.7 \mathrm{~mm}$. The largest grain size with a length of $\sim 8 \mathrm{~mm}$ amongst all investigated samples was determined for the syenite granite disk. The highest average length of $1.9 \mathrm{~mm}$ corresponded to Liberec granite. The probability distribution of grain lengths for Liberec granite had a wider shape (Figure 4a). For this sample, there was an almost complete absence of grains with sizes smaller than $0.5 \mathrm{~mm}$.

We attempted to estimate the structural heterogeneity of mica grains inside granites using the standard deviation of these probability distributions. The lowest value of $0.4 \mathrm{~mm}$ was found for Westerly granite and confirms the choice of reference for homogeneous rock. The standard deviation of the aspect ratio of mica grains for the Mrakotin sample was close to $1 \mathrm{~mm}$. Somewhat higher values of approximately $1.2 \mathrm{~mm}$ were obtained for Liberec granite and syenite. 
a)

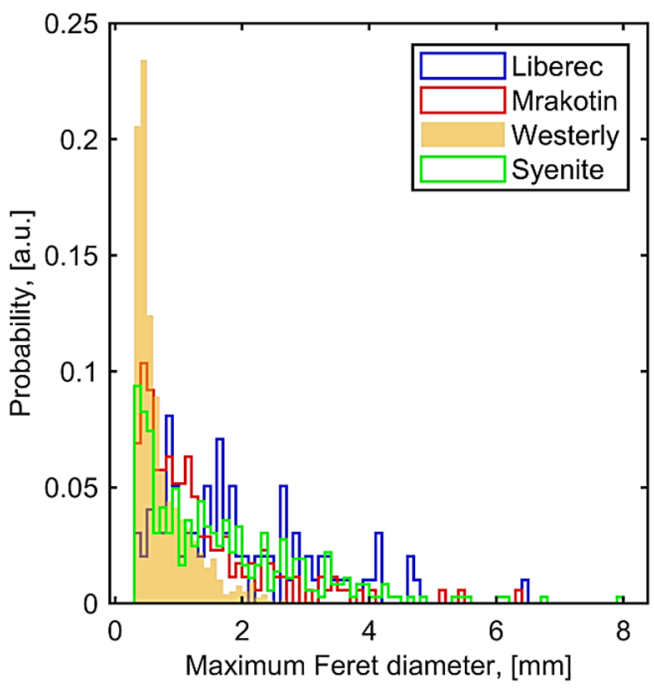

b)

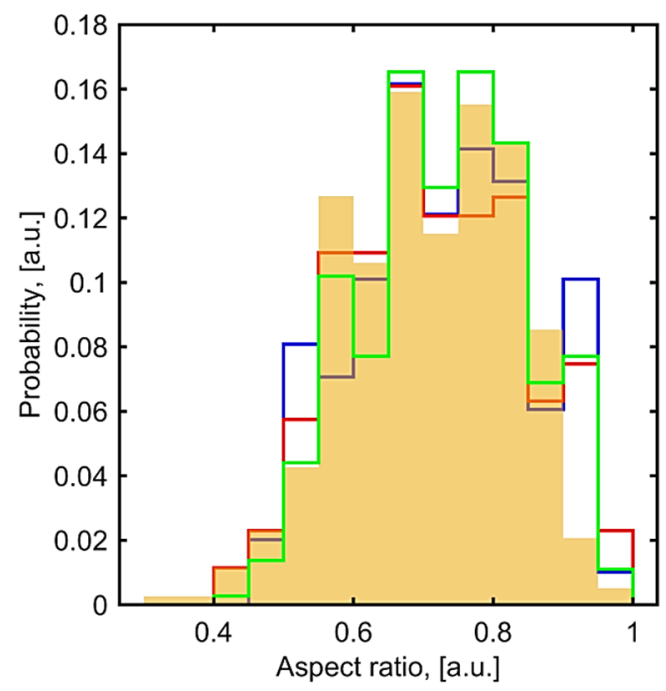

Fig. 4 A photo of the polished upper surfaces of the studied granite disks. Rock forming minerals differ by color: black - biotite, gray - quartz, pink - orthoclase, white - plagioclase and muscovite.

Table 2 The volume and surface related content of the mica phase, $w_{\text {mica }}$, in granite samples obtained from calculations of neutron tomography data.

\begin{tabular}{lcc}
\hline Granite & Surface related slice [\%] & Total volume content [\%] \\
\hline Liberec & 9.9 & 4.8 \\
Mrakotin & 15.2 & 6.3 \\
Syenite & 15.5 & 14.9 \\
Westerly & 5.2 & 3.4 \\
\hline
\end{tabular}

In contrast to differences in size distributions, the aspect ratio variations (Fig. $4 \mathrm{~b}$ ) are much similar for all of the granite samples. The shape of the probability distributions resembles a normal distribution with the same mean value of approximately 0.7. Thus, it describes a rather general property of mica grains, independent of size.

Variability in grain size is one of the indicators of the degree of heterogeneity in granite samples and does not depend on the spatial arrangement of mica grains inside the volume of samples. Character of the spatial distribution is proposed to be described using variations in the mineral composition of the mica phase in corresponding tomographic slices calculated as a relative number of voxels:

$$
w_{\text {mica }}=\frac{\text { Lvoxels of mica }}{\sum \text { voxels of sample }} \cdot 100 \%
$$

Using this formula, we calculated the content of the mica phase in the volume of the disks and the slice corresponding to the real surface of each granite disk. Results obtained from these calculations are provided in Table 2.

The values of mica content on the surface slice are in good agreement with data obtained by the TIMA analysis (Table 1). Values of mica content obtained on the surface and in the volume of the granite sample significantly differed (Table 2), especially for Liberec and Mrakotin samples, suggesting a greater level of heterogeneity for these granites.

For a more detailed examination of heterogeneity in spatial distribution, we followed the variation in mica content across sample volume. Granite samples have non-equal dimensions imposed by the disk-like shape. To analyze heterogeneity in the spatial distribution of mica grains within samples, we propose using the planes for which the dimensions of the sample are uniform: radial planes (parallel to the base plane of disks) and tangent planes (perpendicular to the base plane and going through the center). Hence, if samples are homogeneous, these planes would be almost equivalent and should have a minimal difference in mineral content.

The radial sections of granite disks correspond to the reconstructed tomographic slices and reflect mica distribution with depth. The mica phase distributions calculated for the radial sections are provided in Figure 5a. As seen, samples of Liberec, Mrakotin, and syenite granites have a large variation in the mica phase spatial distribution as compared to the referenced Westerly granite (Fig. 5a). For some depths, the difference in mica content reached $10 \%$. For the Mrakotin disk, major deviations correspond to a solid large grain with a size of $\sim 3.5 \mathrm{~mm}$ on the disk surface (Fig. 1). 
a)

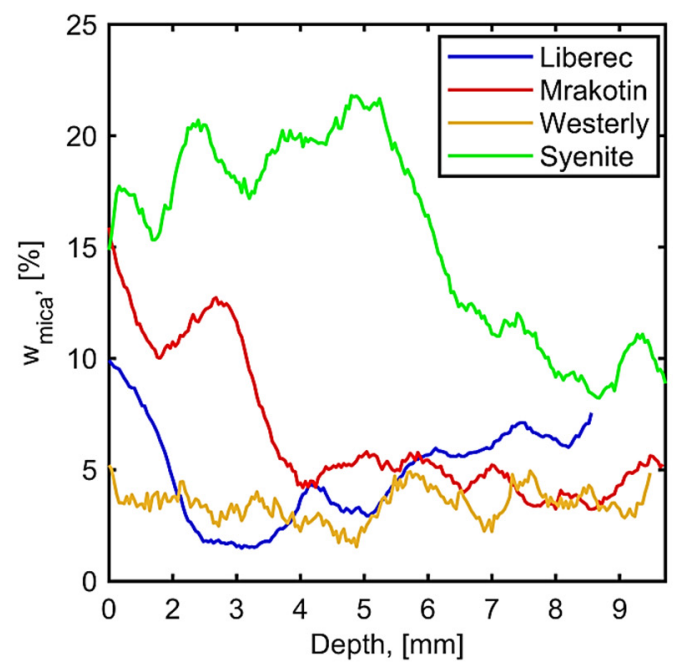

b)

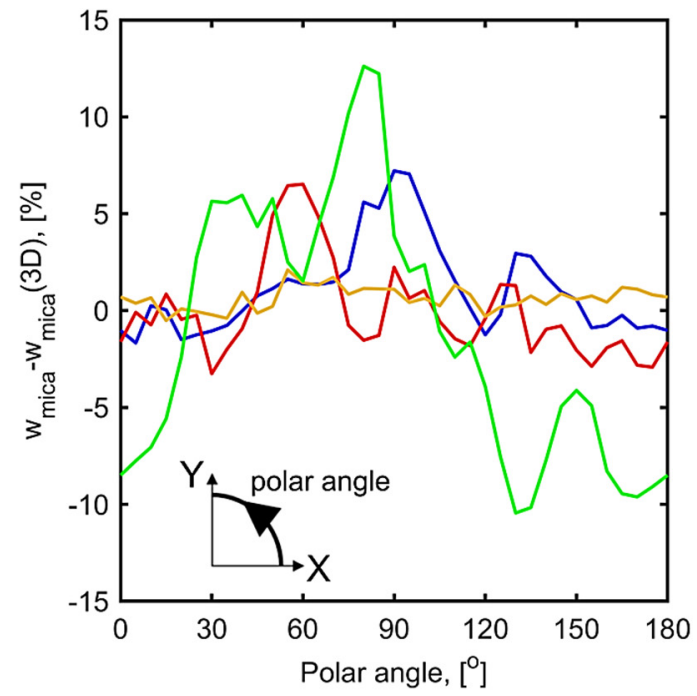

Fig. 5 Variation of the mica content within granite disks: the mica content, $\mathrm{w}_{\text {mica }}$, with the depth of the sample calculated from radial slices (a); angular deviation of the mica content from the bulk value $\left(\mathrm{w}_{\text {mica }}-\right.$ $\mathrm{w}_{\text {mica }}(3 \mathrm{D})$ ), calculated from tangent slices at different polar angles (b). The inset provides the definition of the polar angle and the orientation of axes for radiographic images (Fig. 2a) and tomographic slices.

The tangential distribution of mica phase content was obtained using rotation of the volume of granite disks by the nearest-neighbor interpolation (Kok and Tam, 2019), with the angular collection of the mica content at different polar angles with a step of $5^{\circ}$. Directional dependence within the tangential distribution reflects the anisotropic character of structural heterogeneity in a manner similar to that of physical properties. The difference between $w_{\text {mica }}$, determined in the tangent slices, and the mean value, $w_{\text {mica }}(3 \mathrm{D})$, (Table 2 ) is provided in order to show the anisotropic deviation from homogeneity. Calculated tangential distributions are provided in Figure $5 \mathrm{~b}$.

The most homogeneous distribution of the mica phase corresponds to the Westerly granite sample. In other granites, the angular distributions have a complex behavior corresponding to the presence of specifically oriented planes with a higher mica content. The largest deviations, of more than $10 \%$, correspond to the syenite sample. The distinct peak on the tangential mica distribution of Mrakotin granite relates to the large grain that is visible on the photographic image (Fig. 1).

In accordance with the terminology used in seismic rock studies (Babuska and Cara, 1991), we propose using the coefficient $k=$ $100 \%\left(\max \left(w_{\text {mica }}\right)-\min \left(w_{\text {mica }}\right)\right) / \operatorname{mean}\left(w_{\text {mica }}\right)$ when estimating the anisotropy of the angular distribution of the mica phase within the volume of granites. Then, for the studied granite samples, the anisotropy coefficient, $k$, is $2.2 \%$ for Westerly granite, $10.9 \%$ for Mrakotin granite, $17.5 \%$ for Liberec granite, and $21.9 \%$ for the syenite sample.

As an intermediate conclusion, we note that neutron tomography can be used to successfully obtain structural information regarding both the morphology and spatial arrangement of minerals inside a volume of rocks. We also: 1) presented several algorithms for detecting and describing the anisotropy of the mica phase distribution in granite, 2) proposed several parameters for describing the degree of heterogeneity of the mica grain distribution, and 3) calculated the distribution of mica grains volumes and aspect ratios. Figure 5a also demonstrates the heterogeneity limitation of commonly used 2D methods such as optical and electron microscopy.

\subsection{THE ANISOTROPY OF THE MICA PHASE SPATIAL DISTRIBUTION BY MEANS OF ULTRASONIC SHEAR WAVE MEASUREMENTS}

In the previous section, we indicated possibilities for using the neutron tomography method for studying structural anisotropy within granite samples. Algorithms were proposed for both the analysis of three-dimensional tomographic data and the estimated parameters of spatial anisotropy due to the arrangements of mica grains within the sample volume. To support these structural results, we performed ultrasonic measurements of shear wave propagation in granite samples at different polar angles with a step of 30 degrees. Ultrasonic sounding was performed with a direct, pulse-transmission technique (Aydin, 2013) using a pair of $1 \mathrm{MHz}$ shear sensors (V153, Olympus) placed on the opposite sides of samples. For transferring shear waves into samples, shear gel was used. The polarization of both transmitter and receiver was perpendicular to the base plane of granite disks. The waveforms of ultrasonic shear waves obtained for the base plane of granite disks are provided in Figure 6a. To determine the 
a)

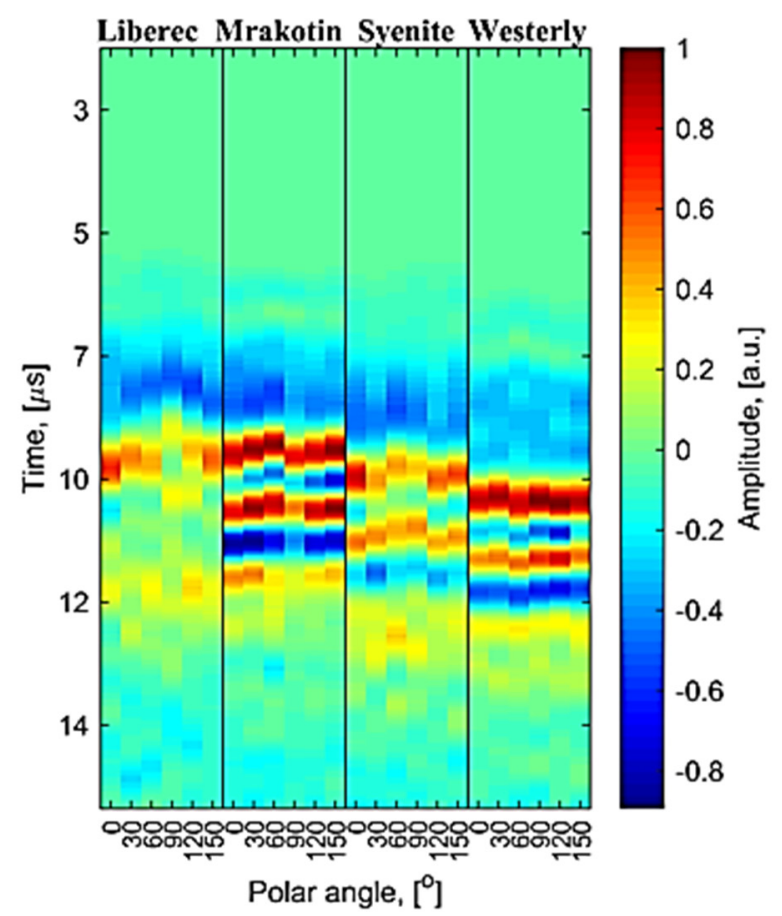

b)

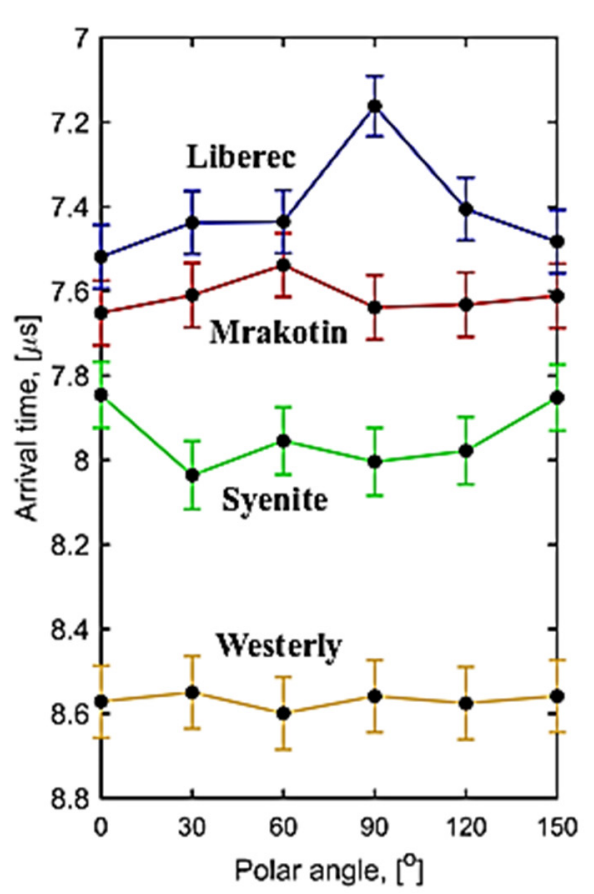

Fig. 6 (a) Ultrasonic shear waveforms measured in the base plane of granite disks in the range of polar angles from $-90^{\circ}$ to $90^{\circ}$ with a $30^{\circ}$ step. The amplitude of each angle trace is normalized on the maximum value. b) Shear wave arrival times, determined from the measured waveforms. Error bars correspond to a $1 \%$ error.

arrival times of shear waves, obtained waveforms were automatically processed using cross-correlation. The corresponding dependencies of arrival times on the measurement directions are provided in Figure $6 \mathrm{~b}$.

Almost no shifts of amplitude in ultrasonic shear waves for all time domains were determined for the reference Westerly granite sample. Such behavior indicates that structural homogeneity exists within the inner volume. For the Mrakotin granite, the first maximum at $\sim 10 \mu$ s on ultrasonic shear waveforms (Fig. 6a) clearly exhibited a dependency on the polar angle while shifts in the other maximums of amplitudes were rather small. The greatest changes in ultrasonic shear waveforms were detected in the measurement directions of syenite and Liberec granite (Fig. 6a). According to neutron tomography results, these samples are the most structurally heterogeneous (see previous section). The travel times of shear waves are also sensitive to the structural heterogeneity. As compared to the arrival times of measured shear waves (Fig. 6b) with angular variations in the mica content (Fig. 5b), we found a good correlation between the maximum and minimum values for both figures, especially for Liberec granite.

The presented results indicate that our anisotropy estimates for studied granites from neutron tomography data are qualitatively consistent with data obtained by ultrasonic shear wave measurements. The Westerly granite selected as the reference sample displayed reliable compliance with the uniform distribution of mica grains, without any layer or foliation formations. Significant differences were also noted between the distribution of mica grains on the slice surface and within the whole volume. The finding may indicate insufficient and erroneous surfacerelated data obtained using typical methods. The problem of correlations between scanning electron microscopy TESCAN and neutron tomography is discussed below.

\subsection{COMPARATIVE CALCULATIONS OF MICA CONTENT FROM ELECTRON AND OPTICAL MICROSCOPY AND NEUTRON TOMOGRAPHY DATA}

The neutron tomography method not only provides the visualization of three-dimensional data but also calculations of the structural distribution of mineral phases within the volume of rock samples. However, particular tasks require a sufficiently high spatial resolution and the application of microscopic or electron scanning methods are required. In our work, we attempted to estimate error limits within calculations of the spatial distribution of the mica phase for neutron tomography and classical methods of optical and electron microscopy. Microscopy methods allowed us to only obtain data from the surface of the sections of studied samples and we compared data from the upper tomography slice using 

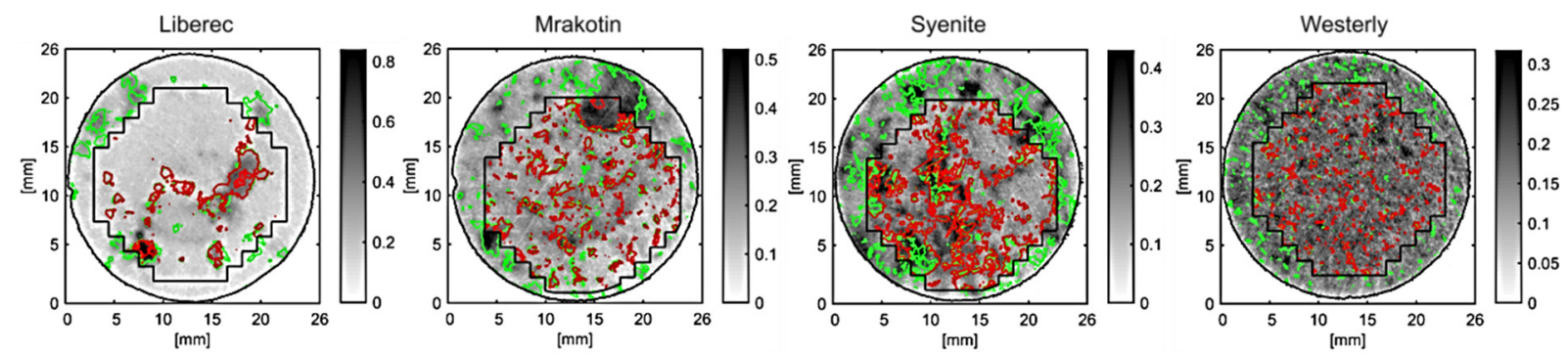

Fig. 7 The overlay of images of sections of granite disks obtained using different methods. The gray images are upper slices obtained from the neutron tomography method. Red contours indicate mica grain boundaries obtained from TIMA TESCAN microscopy. Green contours indicate boundaries of the mica phase obtained from the optical photo. The gray color scales provide a neutron absorption degree in $\mathrm{cm}^{-1}$. The scanning area of the TIMA TESCAN is labeled using a piece-wise solid line.

Table 3 The mica phase content on the surface of granite samples as the pixel number of separated areas of images obtained by the TIMA TESCAN, optical microscopy, and neutron tomography.

\begin{tabular}{lccc}
\hline & $\begin{array}{c}\text { TIMA TESCAN } \\
\text { slice, } \mathrm{px}\end{array}$ & $\begin{array}{c}\text { Optical microscopy } \\
\text { slice, } \mathrm{px}\end{array}$ & $\begin{array}{c}\text { Neutron tomography } \\
\text { slice, } \mathrm{px}\end{array}$ \\
\hline Liberec & 12008 & 17609 & 16596 \\
Mrakotin & 20593 & 20775 & 20722 \\
Syenite & 29343 & 37812 & 30903 \\
Westerly & 10007 & 8152 & 7164 \\
\hline
\end{tabular}

corresponding microscopy data. In other words, TESCAN and optical microscopy images were obtained from the polished side of each granite sample (Fig. 1).

To compare data obtained using these different methods, we converted all of the images to gray-scale patterns. Then, the TIMA TESCAN images and the optical photographs were converted to a binary format with a mica phase separation. An overlay presentation of the TIMA TESCAN, optical microscopy, and neutron tomography slices of the studied granite samples are provided in Figure 7.

The number of pixels per unit area on images, as the corresponding area of the mica phase on the slice, is presented in Table 3.

As can be seen, calculation of the surface-related content of the mica phase of granites displayed similar results, despite differences in the nature of image contrast formation in different methods. We believe that the observed differences are most likely due to differences in spatial resolution and the corresponding choice of boundary conditions for the procedure of the separation of mica and the matrix mineral phases used in the image segmentation procedure.

\section{CONCLUSION}

Morphological calculations based on experimental tomography data were used to analyze the spatial arrangement of the mica mineral phase inside the volume of several granite samples. Sufficient neutron radiography contrasted between the mica phase and other mineral components of the studied granites allowed us to clarify several structural features characterizing the heterogeneous distribution of mica mineral grains inside granite volumes, which in turn, impact formation of the anisotropy of physical properties for granite rocks. Some approaches and algorithms for processing 3D tomographic data were proposed for identifying structural heterogeneity. For recognizing the mica phase, neutron tomography displayed a similar resolution for optical and electron microscopy while offering 3D distribution data. Consistency between the results obtained from neutron tomography and ultrasonic sounding demonstrated the influence of mica distribution on the effective elastic properties of mica bearing rocks.

\section{ACKNOWLEDGEMENTS}

Our study was partly supported by research project 18-08826S, with funding provided by the Czech Science Foundation; by JINR, project No. 044-1121-2015/2020; by the Czech Academy of Sciences, project RVO 67985831; and by a project of the Ministry of the Interior of the Czech Republic, VI20152020035.

\section{REFERENCES}

Aydin, A.: 2013, Upgraded ISRM suggested method for determining sound velocity by ultrasonic pulse transmission technique. The ISRM Suggested Methods for Rock Characterization, Testing and Monitoring, 2007-2014, 95-99. DOI: 10.1007/978-3-319-07713-0_6

Babuska, V. and Cara, M.: 1991, Seismic Anisotropy in the Earth.

Backus, G.E.: 1962, Long-wave elastic anisotropy produced by horizontal layering. J. Geophys. Res., 67, 11, 44274440. DOI: 10.1029/jz067i011p04427 
Boone, M.A., De Kock, T., Bultreys, T., De Schutter, G., Vontobel, P., Van Hoorebeke, L., and Cnudde, V.: 2014, 3D mapping of water in oolithic limestone at atmospheric and vacuum saturation using X-ray micro-CT differential imaging. Mater. Charact., 97, 150-160. DOI: 10.1016/j.matchar.2014.09.010

Chen, R.C., Dreossi, D., Mancini, L., Menk, R., Rigon, L., Xiao, T.Q. and Longo, R.: 2012, PITRE: software for phasesensitive xray image processing and tomography reconstruction. J. Synchrotr. Rad., 19, 836-845. DOI: $10.1107 /$ S0909049512029731

Christe, P., Bernasconi, M., Vontobel, P., Turberg, P. and Parriaux, A.: 2007, Three-dimensional petrographical investigations on borehole rock samples: a comparison between X-ray computed- and neutron tomography. Acta Geotech., 2, 4, 269-279. DOI: $10.1007 / \mathrm{s} 11440-007-0045-9$

Cowie, S. and Walton, G.: 2018, The effect of mineralogical parameters on the mechanical properties of granitic rocks. Eng. Geol., 240, 204-225. DOI: $10.1016 /$ j.enggeo.2018.04.021

Grégoire, V., Darrozes, J., Gaillot, P., Nédélec, A. and Launeau, P.: 1998, Magnetite grain shape fabric and distribution anisotropy vs rock magnetic fabric: a three-dimensional case study. J. Struct. Geol., 20, 7, 937-944. DOI: 10.1016/s0191-8141(98)00022-4

Grêt, A., Snieder, R. and Scales, J.: 2006, Time-lapse monitoring of rock properties with coda wave interferometry. J. Geophys. Res., Solid Earth, 111, B3. DOI: 10.1029/2004jb003354

Hrstka, T., Gottlieb, P., Skala, R., Breiter, K. and Motl, D.: 2018, Automated mineralogy and petrologyapplications of TESCAN Integrated Mineral Analyzer (TIMA). J. Struct. Geol., 63, 1, 47-63. DOI: $10.3190 /$ jgeosci.250

Jones, S.B. and Friedman, S.P.: 2000, Particle shape effects on the effective permittivity of anisotropic or isotropic media consisting of aligned or randomly oriented ellipsoidal particles. Water Resour. Res., 36, 10, 2821-2833. DOI: 10.1029/2000wr900198

Jorand, R., Vogt, C., Marquart, G. and Clauser, C.: 2013, Effective thermal conductivity of heterogeneous rocks from laboratory experiments and numerical modeling. J. Geophys. Res., Solid Earth, 118, 10, 5225-5235. DOI: 10.1002/jgrb.50373

Kichanov, S., Saprykina, I., Kozlenko, D., Nazarov, K., Lukin, E., Rutkauskas, A. and Savenko, B.: 2018 , Studies of ancient Russian cultural objects using the neutron tomography method. J. Imaging, 4, 2, 25. DOI: $10.3390 /$ jimaging4020025

Kok, C.W. and Tam, W.S.: 2019, Digital Image Interpolation in MATLAB $\AA$.

Kozlenko, D.P., Kichanov, S.E., Lukin, E.V., Rutkauskas, A.V., Belushkin, A.V., Bokuchava, G.D. and Savenko, B.N.: 2016, Neutron radiography and tomography facility at IBR-2 reactor. Phys. Part. Nucl. Lett., 13, 3, 346-351. DOI: $10.1134 / \mathrm{s} 1547477116030146$

Merkus, H.G.: 2009, Particle size measurements: fundamentals, practice, quality. $533 \mathrm{pp}$

Murphy, W.F., Roberts, J.N., Yale, D. and Winkler, K.W.: 1984, Centimeter scale heterogeneities and microstratifaction in sedimentary rocks. Geophys. Res. Lett., 11, 8, 697-700.

DOI: 10.1029/g1011i008p00697
Parkhomenko, E.I.: 2012, Electrical properties of rocks. Series. Monographs in Geoscience, Springer US, $1^{\text {st }}$ ed. 1967, 321 pp. DOI: 10.1007/978-1-4615-8609-8

Petružálek, M., Lokajíček, T. and Svitek, T.: 2017, Ultrasonic method for estimation of crack initiation stress. In 51st US Rock Mechanics/Geomechanics Symposium. American Rock Mechanics Association.

Petružálek, M., Lokajíček, T., Svitek, T., Jechumtálová, Z., Koláŕ, P. and Š́lený, J.: 2019, Fracturing of migmatite monitored by acoustic emission and ultrasonic sounding. Rock Mech. Rock Eng., 52, 1, 47-59. DOI: $10.1007 / \mathrm{s} 00603-018-1590-2$

Petružálek, M., Jechumtálová, Z., Šílený, J., Kolář, P., Svitek, T., Lokajíček, T., Turková, I., Kotrlý, M. and Onysko, R.: 2020, Application of the shear-tensile source model to acoustic emissions in Westerly granite. Int. J. Rock Mech. Min. Sci., 128, 104246. DOI: $10.1016 /$ j.ijrmms.2020.104246

Pribnow, D. and Umsonst, T.: 1993, Estimation of thermal conductivity from the mineral composition: Influence of fabric and anisotropy. Geophys. Res. Lett., 20, 20, 2199-2202. DOI: 10.1029/93g102135

Přikryl, R.: 2006, Assessment of rock geomechanical quality by quantitative rock fabric coefficients: Limitations and possible source of misinterpretations. Eng. Geol., 87, 3-4, 149-162. DOI: 10.1016/j.enggeo.2006.05.011

Scales, J.A. and Malcolm, A.E.: 2003, Laser characterization of ultrasonic wave propagation in random media. Phys. Rev. E, 67, 4. DOI: $10.1103 /$ physreve. 67.046618

Schneider, C.A., Rasband W.S. and Eliceiri K.W.: 2012, NIH image to imageJ: 25 years of image analysis. Nat. Methods, 9, 671-675. DOI: 10.1038/nmeth.2089

Sears, V.F.: 1992, Neutron scattering lengths and cross sections. Neutron News, 3, 3, 26-37. DOI: $10.1080 / 10448639208218770$

Shermergor T.D.: 1977, Theory of elasticity of microinhomogeneous media. Nauka, Moscow, (in Russian).

Siegesmund, S. and Dürrast, H.: 2010, Physical and mechanical properties of rocks. Stone in Architecture, 97-225. DOI: 10.1007/978-3-642-14475-2 3

Shushakova, V., Fuller, E.R. and Siegesmund, S.: 2010, Influence of shape fabric and crystal texture on marble degradation phenomena: simulations. Environ. Earth Sci., 63, 7-8, 1587-1601. DOI: $10.1007 / \mathrm{s} 12665-010-0744-7$

Strobl, M., Manke, I., Kardjilov, N., Hilger, A., Dawson, M. and Banhart, J.: 2009, Advances in neutron radiography and tomography. J. Phys. D Appl. Phys., $42,24,243001$. DOI: $10.1088 / 0022-3727 / 42 / 24 / 243001$

Vasin, R., Lebensohn, R.A., Matthies, S., Tomé, C.N. and Wenk, H.-R.: 2014, The influence of grain shape and volume fraction of sheet silicates on elastic properties of aggregates: Biotite platelets in an isotropic matrix. Geophysics, 79, 6, D433-D441. DOI: $10.1190 /$ geo2014-0148.1

Vontobel, P., Lehmann, E. and Carlson, W.D.: 2005, Comparison of X-ray and neutron tomography investigations of geological materials. IEEE T. Nucl. Sci., 52, 1, 338-341. DOI: 10.1109/tns.2005.843672 